\title{
Riesgos Laborales en Trabajadores de Barberías y Peluquerías de Economía Informal. Caracas, Venezuela
}

\author{
OCCUPATIONAL HAZARDS IN BARBERSHOPS AND HAIRDRESSERS WORKERS OF INFORMAL ECONOMY. \\ CARACAS, VENEZUELA
}

\author{
Yohama Caraballo-Arias', Arturo Rafael Rodríguez², Ángel José Rivero², Richard Gerardo Rangel ${ }^{2}$, Marcial Barrios Covaro ${ }^{3}$ \\ 1. Coordinadora del Centro Adherido de la Red Cochrane Iberoamericana. Docente e investigadora, Cátedra de Medicina del Trabajo, Escuela de \\ Medicina Luis Razetti, Facultad de Medicina, Universidad Central de Venezuela. \\ 2. Estudiantes de sexto año de Medicina, Escuela de Medicina Luis Razetti, Facultad de Medicina. Universidad Central de Venezuela. \\ 3. Licenciado en Comunicación Social, publicista. Mundo Ocupacional, C.A.
}

\begin{abstract}
RESUMEN
En Venezuela el sector informal de barberías y peluquerías constituye una fuente de absorción de mano de obra desocupada, que tiene algunas ventajas respecto a ingresos y flexibilización laboral, pero por otro lado es un sector desprotegido y con accesos limitados o nulos a servicios de seguridad y salud laboral, lo que dificulta la inclusión en programas de prevención de accidentes de trabajo y enfermedades ocupacionales.

En este estudio observacional transversal y descriptivo se aplicó "la encuesta de las condiciones de trabajo y salud en América Latina del Center for International Health" y se analizaron las actividades de 40 trabajadores de barberías y peluquerías: 50\% del género masculino y $50 \%$ femenino, 85\% con edades comprendidas entre 20-49 años. De ellos, 65\% manipulaban productos químicos, 62,5\% utilizaban el secador y/o máquina de afeitar, 87,5\% habían sufrido al menos una lesión en su área de trabajo y 100\% refirió adoptar bipedestación prolongada, hacer movimientos repetitivos y presentar algún tipo de trastorno músculo-esquelético, cuyos síntomas más frecuentes fueron dorsalgias y lumbalgias con 37,5\% y 32,5\% respectivamente. Por otro lado, las várices en miembros inferiores fueron la segunda causa de morbilidad reportada.
\end{abstract}

(Caraballo-Arias Y, Rodríguez A, Rivero A, Rangel R, Barrios M, 2013. Riesgos Laborales en Trabajadores de Barberías y Peluquerías de Economía Informal. Caracas, Venezuela. Cienc Trab. Ene-Abr; 15 [46]: 18-23).

Palabras claves: BARBERÍA, RIESGO LABORAL, ENFERMEDAD PROFESIONAL, SALÓN DE BELLEZA, ECONOMÍA INFORMAL.

\section{INTRODUCCIÓN}

En los últimos años se ha venido desarrollando en América Latina una situación de crisis socio-económica de gran impacto, y Venezuela no escapa de ella. La crisis económica se manifiesta

Correspondencia / Correspondence:

Yohama Caraballo-Arias

Universidad Central de Venezuela,

Ciudad Universitaria, Los Chaguaramos Caracas, Venezuela

Tel.: (0058)-426-5187210

e-mail: caraballoy@med.ucv.ve

Recibido: 28 de Febrero 2013 / Aceptado: 03 de Abril de 2013

\section{ABSTRACT}

Some of the barbershops and hair saloons -belonging to the informal sector- are a source of employment which takes in unoccupied work force. This workers have some advantages concerning to income and work flexibility, but in the other hand it is an unprotected sector with limited or nonexistent access to Occupational, Safety and Health services. This situation makes difficult to include them in labor accident occupational disease prevention programs. A cross-sectional and descriptive study was carried out in which 40 barbershop and hair saloon workers were surveyed. Their activities were analyzed, employing the "survey of work and health conditions in Latin America of the Center for International Health". Of these workers, 50\% were male and 50\% female, and 85\% were between 20 to 49 years old. $65 \%$ used chemical products, $62,5 \%$ used hair dryers and/or shaving machines, $87,5 \%$ had suffered some form of workplace injury, and all of them admitted to have adopted prolonged standing postures, to make repetitive movements, suffering at least from any musculoskeletal disorder. The second disease reported were varicose veins.

Key words: HAIRDRESSING, BARBERING, OCCUPATIONAL RISK, OCCUPATIONAL DISEASES, INFORMAL ECONOMY. en el deterioro del poder adquisitivo, elevados niveles de pobreza y en el gran auge de los índices de desempleo. A raiz de esto surge la economía informal, la cual tiene un importante potencial para crear trabajo e ingresos por su relativo fácil acceso y por tener mínimas exigencias en materia de educación, calificación, tecnología y capital. , $2,3^{2}$

El Instituto Nacional de Estadísticas (INE) en el "Informe mensual en la situación de fuerza de trabajo en Venezuela junio 2012, sección 5.2 Población informal”, define a los trabajadores del sector informal como "aquellas personas que laboran en empresas con menos de cinco personas empleadas (incluido el patrono), servicio doméstico, trabajadores por cuenta propia no profesionales (tales como vendedores, artesanos, conductores, pintores, carpinteros, buhoneros, entre otros) y ayudantes o auxiliares que no son remunerados y que trabajan 15 horas o más semanalmente". Este instituto realizó un análisis comparativo de la 
población ocupada en el sector informal que demostró que en junio de 2011 era de 5.176.970 personas, mientras que en el mes de junio del año 2012 fue de 5.400.667, lo cual muestra un incremento de 223.697 personas (equivalente a un 4,1\%). ${ }^{4}$

La Organización de las Naciones Unidas (ONU) define economía informal como:

El conjunto de actividades económicas desarrolladas por los trabajadores y las unidades económicas que, tanto en la legislación como en la práctica, están insuficientemente contempladas por sistemas formales o no lo están en absoluto. Las actividades de esas personas y empresas no están recogidas por la ley, lo que significa que se desempeñan al margen de ella; o no están contempladas en la práctica, es decir, que si bien estas personas operan dentro del ámbito de la ley, ésta no se aplica o no se cumple; o la propia ley no fomenta su cumplimiento por ser inadecuada, engorrosa o imponer costos excesivos ${ }^{5}$.

Por otro lado, la Wiego (Women in Informal Employement Globalizing and Organizing) establece que el sector informal refleja el trabajo que se lleva a cabo en las empresas no constituidas, que no están registradas y/o pequeñas. Sin embargo, hay otros tipos de empleo informal fuera de las empresas informales: por ejemplo, las personas que trabajan en empresas formales que no están cubiertas por la protección social, así como los trabajadores domésticos, los trabajadores a destajo, y los familiares de trabajadores que no están cubiertos por la protección social. ${ }^{6}$

En este artículo se abordan los principales riesgos de los barberos y peluqueros, quienes fueron los primeros cirujanos de la historia. Éstos hacian cirugías menores, "sangrías", entre otros procedimientos. En el siglo XIV se fundaron las primeras Cofradías de Barberos y Cirujanos, quienes para poder ejercer debían ser examinados por dos cirujanos de la cofradía. La tienda o barbería normalmente solía estar en el portal de una casa, que generalmente era en la que vivía el barbero. Entre los siglos XV y XVI existía un predominio de los barberos sobre los médicos y cirujanos en los primeros pobladores de América, hasta el punto de convertirse en muchas ocasiones en el único referente a quien acudir en caso de enfermedad. Dada la escasez de médicos y cirujanos en las colonias, la figura del barbero-sangrador se convirtió en un elemento esencial en la medicina colonial, pues tuvo una gran actividad, además de introducir la odontología en el nuevo mundo. ${ }^{7}$

La palabra barbero proviene del latín barba, y se refiere a "la persona que tiene por oficio cortar, afeitar, embellecer o arreglar la barba de los hombres"8 y peluquera/o es la "persona que tiene por profesión el arreglo del cabello de las personas, incluyendo operaciones como lavado, corte, peinado, teñido, entre otros". ${ }^{9}$ Los peluqueros están generalmente especializados en el tratamiento del cabello de un género específico, masculino o femenino, si bien cada vez abundan más los establecimientos unisex, dedicados indistintamente a personas de cualquier sexo.

Todos los trabajos generan riesgos, y éstos se definen según la Norma Técnica del Programa de Seguridad y Salud en el Trabajo (NT-01-2008) como "la probabilidad de que ocurra daño a la salud, a los materiales o ambos". ${ }^{10}$ El oficio de barbero y peluquero no queda exento de riesgos por implicar el uso constante de numerosos productos químicos, donde la temperatura del área laboral y el uso de movimientos repetitivos y esfuerzos físicos aumenta la probabilidad de padecer enfermedades de origen ocupacional. Estas están definidas en el artículo 70 de La Ley
Orgánica de Prevención, Condiciones y Medio Ambiente de Trabajo (Lopcymat) como los "estados patológicos contraídos o agravados con ocasión del trabajo o exposición al medio, en el que la trabajadora o el trabajador se encuentra obligado a trabajar, tales como los imputables a la acción de agentes físicos y mecánicos, condiciones disergonómicas, meteorológicas, agentes químicos, biológicos, factores psicosociales y emocionales, que se manifiesten por una lesión orgánica, trastornos enzimáticos o bioquímicos, trastornos funcionales o desequilibrio mental, temporales o permanentes". ${ }^{11}$ Hoy en día son un problema de salud pública por estar afectando a un alto porcentaje de personas alrededor del mundo. ${ }^{12}$

\section{Materiales y métodos:}

Con el fin de determinar los riesgos laborales a los cuales los trabajadores de peluquería y barbería se exponen, se realizó un estudio observacional transversal y descriptivo en los meses de junio-julio del 2012.

Se planteó la investigación en el Bulevar de Sabana Grande (la mayor calle peatonal de Caracas), el cual posee 1.500 metros de longitud y una superficie aproximada de $27.000 \mathrm{mt}^{2}$ y tiene 3 estaciones de metro. ${ }^{13}$ Este bulevar posee doce establecimientos de belleza distribuidos entre barberías y peluquerías unisex, de los cuales se estudiaron 8 (66,6\%), que aceptaron participar en el presente estudio.

Se obtuvo la autorización de los dueños de los establecimientos y el consentimiento informado de los trabajadores para realizar las observaciones y aplicar el cuestionario para la recolección de datos. La muestra estuvo constituida por 40 trabajadores del género masculino y femenino de barberías y peluquerías donde se realizaron entrevistas personales y la aplicación de la "encuesta de las condiciones de trabajo y salud en América Latina del Center for International Health". Esta encuesta está estructurada en cinco secciones generales y tres módulos. Incluye las dimensiones de condiciones de empleo (9 items), condiciones de trabajo (58 items, sobre aspectos de seguridad, higiene, ergonomía y psicosociología), amenazas y violencias en el trabajo (7 items) y estado de salud (11 items), además de la escala del Cuestionario General de Salud de Goldberg (GHQ-12). ${ }^{14}$

La primera sección consta de tres preguntas generales: género, edad y lugar donde se realizó la entrevista.

La segunda sección incluye aspectos sobre las condiciones de empleo: tipo de contratación y salario neto mensual (adaptado en bolívares) de los últimos tres meses.

La tercera sección trata aspectos sobre las condiciones de trabajo: condiciones disergonómicas, factores psicosociales, humedad, iluminación, productos tóxicos, ruido, temperatura y vibración.

La cuarta sección aborda las amenazas y violencia en el trabajo: acoso sexual, violencia física y psicológica; y la quinta consta de preguntas relacionadas con el estado de salud (física y mental). Al final de la encuesta se presentan tres módulos: el primero corresponde a la salud respiratoria, especificado en la presencia de episodio de disnea súbita, tos, sibilantes y rinitis en los últimos 12 meses y hábito tabáquico. El segundo módulo se refiere a los problemas músculo-esqueléticos en los últimos 12 meses y 7 días, relacionados con dolor, disconfort o adormecimiento del cuello, hombros, codos, manos, muñecas, columna dorsal, columna lumbar, cadera, piernas, rodillas y tobillos. Y el tercer módulo corresponde al estrés en el lugar de trabajo, basado en preguntas con respecto a la desconexión de los problemas del 
trabajo estando en casa o en vacaciones, y las consecuencias de los cambios de estado de ánimo por el lugar de trabajo.

Se realizó la observación de las actividades, tareas y condiciones de trabajo. Se determinó el uso de sustancias químicas más frecuentes, así como su composición química. Además, se evidenció posiciones y posturas disergonómicas, relación social con los compañeros de trabajo y se evaluó el contacto con las herramientas de uso común. Una vez recolectados los datos se procedió a la tabulación y realización de los estudios estadísticos respectivos.

\section{RESULTADOS}

Se evidenció que los empleados del género masculino generalmente sólo se dedicaban a cortar el cabello masculino y las empleadas del género femenino se dedicaban a cortar, secar, pintar y colocar productos al cabello femenino. No obstante, los trabajadores pueden realizar ambas labores independientemente de su género.

En este estudio se encuestaron 40 trabajadores, 50\% del género masculino y 50\% del femenino. El 37,5\% tenía entre 20 y 29 años; el 47,5\% entre 30 a 49 años, y el 15\% más de 50 años. El 40\% tenía menos de un año; el 30\% entre 1 a 5 años, y un 30\% más de 5 años de antigüedad laboral.

$\mathrm{Al}$ evaluar las condiciones laborales se determinó que los días laborales son de libre elección. Se encontró que 62,5\% trabaja 6 días a la semana, 17,5\% 5 días, 15\% 7 días y 5\% 4 días. En cuanto a los turnos laborales se evidenció que 95\% de los trabajadores laboraban el turno de mañana a tarde y un 5\% solo laboraban en la mañana. Perciben una ganancia porcentual según los clientes atendidos, y cuyo promedio neto mensual en los últimos 3 meses es de 4.300 bolívares, equivalente a 1.000 dólares, lo cual representa más del doble del salario mínimo en Venezuela (que es, al momento del estudio, de 2.047,48 bolívares, es decir, 476,15 dólares).

El 55\% de los locales eran cerrados, y el 45\% eran semicerrados $\mathrm{y}$ en todos los casos contaban con aire acondicionado.

En los locales evaluados no sólo se realizan cortes de cabello, sino además actividades estéticas en manos y pies, y en las cuales se usan múltiples productos.

Riesgos físicos:

Un $87,5 \%$ de los encuestados se quejó de una iluminación deficiente. Las vibraciones segmentarias a las que están expuestos los trabajadores dependen del requerimiento del cliente y día de la semana. El 62,5\% utiliza el secador y/o máquina de afeitar de 5 a 15 minutos por cliente, cuyas frecuencias son de $80 \mathrm{~Hz}$ y 60

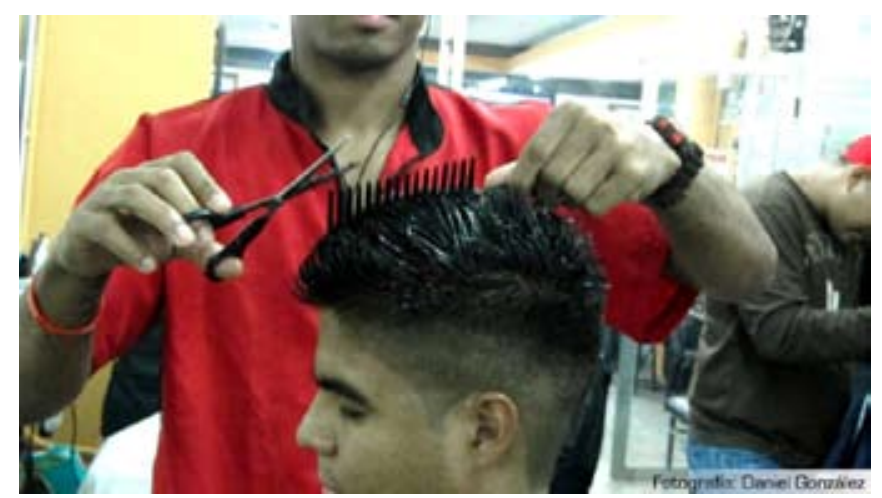

$\mathrm{Hz}$ respectivamente ${ }^{15} \mathrm{y}$ el restante $37,5 \%$ de los trabajadores usa las herramientas de 16 a 35 minutos. En Venezuela, por resolución ${ }^{16}$, se prohíbe fumar en los lugares públicos y de trabajo, por lo tanto los trabajadores no están expuestos al humo de tabaco.

Riesgos químicos:

El 65\% manipulaba productos como: desrriz, sustancias decolorantes, gel para cabello, queratina y pinturas acrílicas. El champú, tintes y acondicionador contienen colágeno soluble (Crotein Q), que puede causar dermatitis irritativa y eczema, siendo esta última el trastorno dermatológico más frecuente en este oficio. ${ }^{17}$ El 75\% de los trabajadores refirió inhalar gases tóxicos en el ejercicio de sus funciones, que según algunos trabajadores son intolerables y les produce molestias respiratorias. 15\% tiene diagnóstico de rinitis, y afirma que se intensifican con las sustancias usadas en el área de trabajo. Muchos de estos productos contienen amoniaco, ácido acético, peróxido de hidrógeno, hidróxido de amonio, 2-metil resorcinol, p-aminofenol, cetearet, crotein $\mathrm{Q}$, sustancias que producen trastornos nasales y dermatitis de contacto tipo irritativa. ${ }^{18}$

Uno de los trabajadores de la muestra estudiada presentaba una dermatosis de presunto origen ocupacional.

Riesgos mecánicos y de accidentes:

En el artículo 69 de la Lopcymat se define los accidentes de trabajo como "todo suceso que produzca en el trabajador o trabajadora una lesión funcional o corporal, permanente o temporal, inmediata o posterior, o la muerte, resultante de una acción que pueda ser determinada o sobrevenida en el curso del trabajo. ${ }^{11} \mathrm{Y}$ se define a los factores de riesgo mecánico como “objetos, máquinas, equipos, herramientas que por sus condiciones de funcionamiento, diseño o por la forma, tamaño, ubicación $\mathrm{y}$ disposición tienen la capacidad potencial de entrar en contacto con las personas o materiales, provocando lesiones en la primera o daños en los segundo". ${ }^{19}$ El $87,5 \%$ de la población refirió que ha sufrido alguna lesión debido a un accidente en su área de trabajo, que le ha obligado a ausentarse del mismo al menos un día además del día del accidente.

Riesgos disergonómicos:

Todos los trabajadores en el área de barbería y peluquería refirieron mantener bipedestación prolongada y realizar movimientos repetitivos, de los cuales 95\% dijo que el sitio dentro del área laboral les permite trabajar con comodidad por ser un sitio amplio donde se pueden desplazar fácilmente. No obstante, el 62,5\% afirmó realizar posturas forzadas, el $87,5 \%$ fuerza la vista por la iluminación inadecuada y 27,5\% considera excesivo su trabajo. También se reportaron trastornos músculo-esqueléticos en miembros inferiores $\mathrm{y}$ dolor lumbar.

Se evaluaron los trastornos músculos-esqueléticos (molestias, dolor, disconfort o adormecimiento) de los barberos y

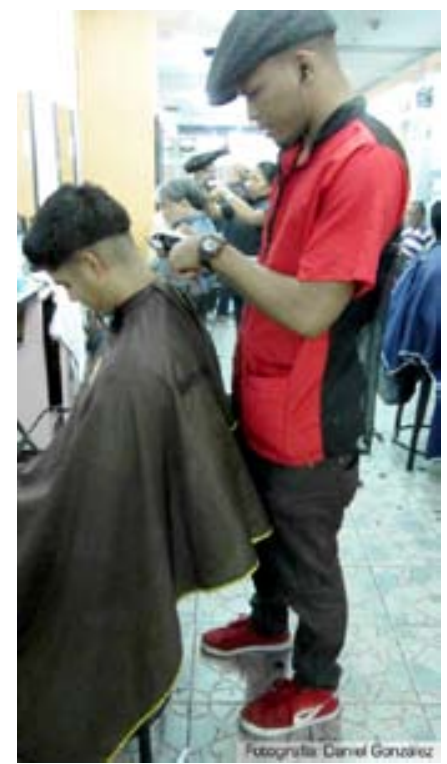




\section{Gráfico 1.}

Distribución porcentual de trastornos músculo-esqueléticos.

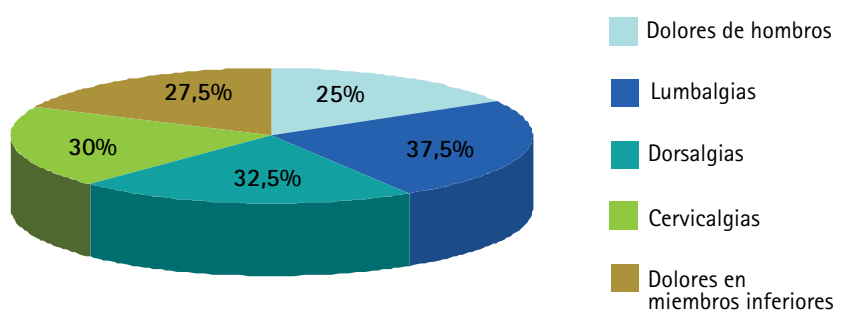

peluqueros en el último año y en los últimos 7 dias, y muy específicamente que le hayan impedido hacer el trabajo de manera efectiva. Los trastornos que predominaron por frecuencia fueron, en primer lugar, lumbalgia; seguido de dorsalgias, cervicalgias, dolores en miembros inferiores ocasionados en parte por la bipedestación prolongada y posturas forzadas; dolor en hombros y dolor en mano/ muñeca, que pueden ser ocasionados por el uso de herramientas. Y por último, dolores en rodillas y tobillos. Los síntomas discapacitantes fueron: 7,5\% dolor en hombros, 5\% lumbalgias y dorsalgias con la misma proporción.

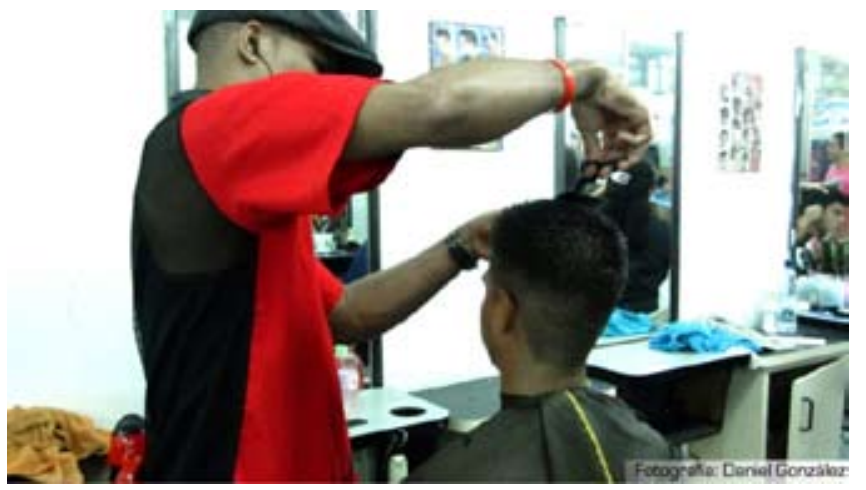

Los trabajadores refirieron que el sitio del local asignado para realizar dichas labores era adecuado para desplazarse cómodamente; sin embargo, se observó que durante su jornada laboral muchos de éstos adoptaban posturas forzadas e incómodas debido al espacio reducido. El 22,5\% manifestó tener várices en miembros inferiores.

Factores psicosociales laborales:

17,5\% afirmó "costarle desconectarse después del trabajo", el 15\% "piensa en los problemas del trabajo estando en su casa", el 17,5\% "piensa en los problemas del trabajo incluso en las vacaciones", el $20 \%$ afirmó que "a veces se ponen de mal humor cuando otras personas se dirigen a ellos", y la misma proporción consideró que "de vez en cuando se sienten constantemente en nervios", el 15\% "se enfada con facilidad", y un 22,5\% "se irrita aunque en realidad no lo quiere".

La auto-percepción de la salud mostró que el 20\% consideró su salud como excelente, el 32,5\% muy buena, el 32,5\% buena y el 15\% regular. En los problemas cardiológicos se encontró que el 42,5\% tiene diagnóstico de hipertensión arterial y recibe tratamiento.

Riesgos biológicos: se observó el recambio de las hojillas de afeitar por cada cliente en las diferentes barberías y peluquerías.

Identificar los riesgos a los cuales están expuestos los barberos y peluqueras es el primer paso para la elaboración de las medidas preventivas. Al finalizar este estudio se elaboró un tríptico informa-
Gráfico 2.

Distribución porcentual de morbilidad reportada. Morbilidad reportada

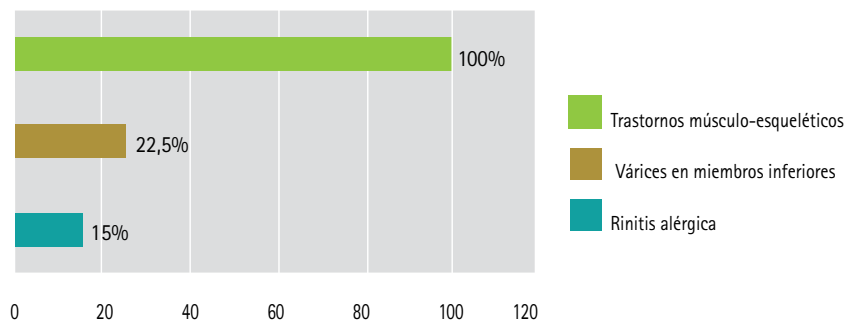

tivo para los trabajadores encuestados de los diferentes locales con recomendaciones y medidas de prevención de enfermedades y accidentes de trabajo. ${ }^{20}$

\section{DISCUSIÓN}

El uso de "la encuesta de las condiciones de trabajo y salud en América Latina del Center for International Health" permitió obtener de una manera fácil y sistematizada los riesgos más importantes en el sitio de trabajo. Sin embargo, se recomendaría utilizar un instrumento diseñado para la ocupación particular de barberos y peluqueros que incluya otros aspectos no abordados en este estudio.

Los factores de riesgo más significativos en este estudio fueron los físicos, químicos, mecánicos y disergonómicos, siendo este último el de mayor impacto.

Los síntomas predominaron en la región lumbar seguido de miembros superiores, cuya elevación constante de hombros son un factor de riesgo importante de molestias a ese nivel. ${ }^{21}$ Por otro lado, la bipedestación prolongada de los barberos y peluqueros son un factor generador de dolores lumbares y en miembros inferiores en este oficio ${ }^{22,23}$, y la presencia de várices en miembros inferiores, también ocasionada o agravada por la misma causa. ${ }^{24,25}$

En cuanto a los riesgos físicos, la exposición prolongada a las vibraciones del secador y la máquina de afeitar puede provocar sindrome del túnel carpiano. Sin embargo, en este estudio no se manifestaron signos y sintomas relacionados con dicho trastorno. $^{26}$

En relación con los riesgos químicos, en Finlandia la bronquitis crónica ocupó el primer lugar de las enfermedades respiratorias más comunes de los trabajadores en peluquerías, lo cual demuestra que el riesgo de padecer esta afección es mayor en este tipo de actividad laboral en relación con la población en general. La rinitis alérgica, tercera causa de morbilidad en este estudio, puede ser ocasionada por la exposición a agentes irritantes encontrados en los productos de uso más común. ${ }^{27}$ Otro estudio confirma la presencia de asma ocupacional en trabajadores de peluquerías asociada a los antecedentes de atopia, actividades durante su primer año de trabajo y dieta, estableciendo que la asociación de estos tres factores condiciona a la aparición de asma ocupacional. ${ }^{28}$ Un metaanálisis realizado en España con datos tomados de EE.UU. y varios paises de Europa reporta que los trabajadores de peluquerías y barberías están expuestos a múltiples sustancias tóxicas como formaldehído, metacrilatos $\mathrm{y}$ nitrosaminas, las cuales son potencialmente carcinogénicas, $\mathrm{y}$ 
algunas de ellas se han encontrado en la orina de los trabajadores dedicados a este oficio. Por lo tanto, concluyen que los peluqueros y ocupaciones afines tienen un mayor riesgo de cáncer que la población en general. El aumento del riesgo es sustancial para pulmón, laringe y vejiga y favoreciendo la aparición del mieloma múltiple y, menos marcada, la enfermedad de Hodgkin, linfoma no Hodgkin, leucemia, ovario, mama, riñón y el cáncer de colon. ${ }^{29}$

Los riesgos biológicos no fueron abordados en la encuesta utilizada; no obstante, se logró determinar según la observación directa que los métodos de desinfección de los materiales usados eran alcohol absoluto y germicidas (bromuro de lauril, dimetil bencil amonio). Estudios han determinado la presencia de agentes infecciosos como hongos en las herramientas de uso común y las superficies de contacto en los salones de belleza y pueden jugar un papel importante en la propagación de las infecciones micóticas entre las personas. ${ }^{30}$ Otros estudios han determinado mediante técnicas de biología molecular (PCR) la presencia de virus de la hepatitis B (VHB) en las cuchillas de afeitar, lo que genera un riesgo de transmisión. De allí la importancia de diseñar y ejecutar programas de prevención y promover técnicas adecuadas de esterilización, así como la prohibición de la reutilización de las hojillas. ${ }^{31}$

En el grupo de trabajadores evaluados se determinó que la carga cuantitativa es variable: va desde intensas horas de trabajo a períodos de mínima actividad; por otro lado, resaltan factores psicosociales protectores como la flexibilidad laboral que les permite realizar actividades extras y compartir con su familia, la libertad de tomar decisiones y las buenas relaciones con colegas y supervisores; no obstante, para profundizar en detalles sería necesario incluir instrumentos desarrollados para la identificación de otros factores y conocer que la exposición a factores psicosociales no deteriora necesariamente la salud del trabajador, son una fuente de riesgo, pues si el individuo utiliza estrategias de afrontamiento funcionales podrá manejar la situación laboral para eliminarlas, o podrá modificar su comportamiento, sus cogniciones o sus emociones para adaptarse a la situación y convivir con ella. ${ }^{32}$ Tal como se determinó en este estudio, los accidentes que con frecuencia afectan este oficio son: caídas de igual o distinto nivel, cortes, contactos eléctricos, contactos con sustancias peligrosas y condiciones disergonómicas. ${ }^{33}$

Concluimos reafirmando que la prevención de enfermedades relacionadas con el trabajo y la promoción de la salud debe ser parte medular en cualquier ámbito laboral. Al finalizar este estudio se informó a cada trabajador sobre el manejo adecuado y práctico de las herramientas de trabajo, de los riesgos a los cuales están expuestos y se ofrecieron recomendaciones y medidas de prevención. Lamentablemente, las carencias de políticas siguen contribuyendo a la informalidad, y así dan lugar a esta economía que representa un refugio para aquellos que, de otro modo, carecerían de empleo, de oportunidades de negocio o de fuentes de ingreso. ${ }^{2,3,5}$

En Venezuela el sector informal constituye una gran fuente de absorción de mano de obra desocupada, y desde finales de los 90 se convirtió en el primer sector generador de ocupación en la economía, como ha sucedido en gran parte de América Latina y el Caribe, fenómeno acentuado por los procesos de globalización, flexibilización y precarización de las relaciones laborales en el mercado de trabajo. ${ }^{34}$

En este estudio se determinó que en líneas generales las condiciones de este sector de trabajadores no son precarias, pues obtienen mayores beneficios económicos que el común de la población; evaden el pago de impuestos, tienen mayor flexibilidad con los horarios. No obstante, y tal como lo demuestra la literatura, este sector no tiene acceso a servicios de seguridad y salud ocupacional, de los cuales sólo lo disfrutan un 10-15\% de los trabajadores del mundo ${ }^{35}$, lo que pudiesen mantener y perpetuar condiciones insalubres y riesgos en el sitio de trabajo que de no corregirse pudiesen generar accidentes de trabajo y enfermedades ocupacionales debido a los múltiples riesgos a los cuales están expuestos.

\section{AGRADECIMIENTO}

A Daniel González, Antonio Marcano, Roberto Fontana, Mundo Ocupacional C.A. y especialmente a los barberos y peluqueros, quienes brindaron su tiempo y apoyo para la realización de este trabajo. 
1. Ramírez D, Velásquez A. Caracteristicas de la buhoneria en el sector informal de la economía. Caso: Sabana Grande, área metropolitana de Caracas. [Trabajo de grado especialización relaciones industriales] [en línea]. Caracas: Universidad Católica Andrés Bello; 2006 [consultado feb 2013]. Disponible en: http://biblioteca2.ucab.edu.ve/anexos/biblioteca/ marc/texto/AA07159.pdf

2. Bustamante $M$, Díaz $R$, Villarreal P. Economía informal: un análisis al comercio ambulante de la región del Maule, Chile. Fórum empresarial. 2009; 14(1):37-61.

3. Portes $A$, Haller W. Políticas sociales: La economia informal [en línea]. Santiago de Chile, CEPAL; 2004 [consultado feb 2013]. Disponible en: http://www.cepal. cl/publicaciones/xml/5/20845/sps100_lcl2218.pdf

4. Instituto Nacional de Estadistica (INE). Situación en la fuerza de trabajo de Venezuela; Informe mensual, mes de junio 2012 [en línea]. Caracas: INE; 2012. [consultado feb 2013]. Disponible en: http://www.ine.gov.ve/documentos/ Social/FuerzadeTrabajo/pdf/Informesemestral.pdf

5. Organización de las Naciones Unidas (ONU). México, tercer lugar en economia informal, de acuerdo con la ONU [en línea]. México, ONU; 2012 [consultado feb 2013]. Disponible en: http://vivirmexico.com/2012/01/mexico-tercer-lugar-en-economia-informal-de-acuerdo-con-la-onu

6. Women in Informal Employment: Globalizing and Organizing (WIEGO). Informal Economy: concepts, definitions y methods [en línea]. Manchester: WIEGO; 2012. [consultado feb 2013]. Disponible en : http://wiego.org/informal-economy/concepts-definitions-methods

7. Expósito R. Barberos y sangradores en Iberoamérica. Cultura de los cuidados. 2011;40(29):31-46.

8. Waheed $\mathrm{Y}$ et al. Awareness and rick factors associated with barbers in transmission of hepatitis $B$ and $C$ from Pakistani population: barber's role in viral. Asian Biomedicine. 2010;4(3):435-442.

9. Proyecto de ley 218 de 2012 cámara, por la cual se formaliza el ejercicio de la actividad de peluqueria y se dictan otras disposiciones [en línea]. Cámara de Representantes, Congreso de Colombia (28 nov 2012) [consultado feb 2013]. Disponible en: http://servoaspr.imprenta.gov.co:7778/gacetap/gaceta.mostrar_ documento?p_tipo $=05 \& p \_n u m e r o=218 \& p \_c o n s e c=34957$

10. Venezuela. Institutos Nacionales de Prevención, Salud y Seguridad Laborales (Inpsasel). Norma técnica para la elaboración de un programa de seguridad y salud en el trabajo [en línea]. Caracas: Inpsasel; 2008 [consultado feb 2013]. Disponible en: http://www.inpsasel.gob.ve/moo_doc/NOR_TEC_PRO_SEG_ SAL_TRA.pdf

11. Ley Orgánica de Prevención, Condiciones y Medio Ambiente de Trabajo: Lopcymat ( 26 jul 2005). Gaceta Oficial (Caracas). 2005;(38.236).

12. Parra M. Conceptos básicos en salud laboral. Santiago de Chile: OIT; 2003. pp. 1-33.

13. Ochea $M$, Vivas V, Miller M. Bulevar de Sabana Grande: diagnóstico integral para su rehabilitación. Parte II [en línea]. Caracas: PDVSA; 2009 [consultado feb 2013]. Disponible en: http://www.vivesabanagrande.com/uploaded/pdf/ Parte\%202\%20diagnostico\%20integral.pdf

14. Benavides et al. Conjunto mínimo básico de ítems para el diseño de cuestionarios sobre condiciones de trabajo y salud. Arch Prev Riegos Labor 2010; 13(1):13-22.

15. Organización Mundial para la Salud. Campos electromagnéticos (CEM) [en linea]. Ginebra: OMS; 2012 [consultado feb 2013]. Disponible en: http://www. who.int/pehemf/about/WhatisEMF/es/index3.html

16. Ley antitabaco No. 030. De la República Bolivariana de Venezuela. Ministerio del Poder Popular para la Salud (2 mar 2011). Gaceta Oficial (Caracas). 2011; (39.627).

17. Takkouche B, Regueira C, Montes A. Risk of cancer among hairdressers and related workers: a meta-analysis. Int J Epidemiol. 2009; 38:1512-1531.

18. CRODA. Personal care product guide [en línea]. Sofia: Hobbytakt; 2010 [consultado feb 2013]. Disponible en: http://www.hobbytakt.com/products/ 8097649860.pdf

19. Henao F. Introducción a la salud ocupacional. Bogotá: Ecoe; 2007. p.55.

20. España. Asociación de la Industria Navarra (AIN).Trabajadores autónomos y prevención de riesgo: peluquerías [en línea]. Pamplona: AIN; 2011 [consultado feb 2013]. Disponible en: http://www.lineascen.cenavarra.es/documentos/ ficheros_recursos/Peluquerias.pdf

21. Wahlstrom J et al. Upper Arm Postures and Movements in Female Hairdressers across Four Full Working Days. Ann Occup Hyg. 2010;54 (5):584-594.

22. Rubio G, Del Barrio A, Ruiz C. Factores de riesgo y patología lumbar ocupacional. Mapfre medicina. 2001;12 (3):204-213.

23. Escalona, E. Trastornos músculo-esqueléticos en miembros inferiores: condiciones de trabajo peligrosas y consideraciones de género. Salud en los trabajadores. 2001;9(1):23-33.

24. Espinola F. Prevalencia de várices en miembros inferiores en el personal del Hospital de Clínicas. Rev Chil Cir. 2007; 59 (5): 342-347.

25. Herrera $A$, Henríquez M, Daza D. Factores de riesgo, signos y síntomas de posible origen ocupacional, en trabajadores de tres peluquerias del este de la ciudad de Barquisimeto. Acta Científica Estudiantil. 2009;7(4):258-26.

26. Palmer K. Carpal tunnel syndrome: the role of occupational factors. Best Pract Ret Clin Rheumatol. 2011;25(1):15-29.

27. Leino $T$, Tammilehto L, Luukkonen R, Nordman $H$. Self reported respiratory symptoms and diseases among hairdressers. Occup Environ Med. 1997; 54:452-455.

28. Rémen T, Acoutey D, Paris C, Zimirou-Navier D. Diet, occupational exposure and early asthma incidence among bakers, pastry makers and hairdressers. BMC Public Health. 2012;12:387.

29. Doutre M. Occupational contact urticaria and protein contact dermatitis. Eur J Dermatol. 2005;15 (6):419-424.

30. Usluh Uyanik M, Ayilldiz A. Mycological examination of the barbers' tools about sources of fungal infections. Mycoses. 2008;51(5):447-450.

31. Eroglu $C$, Zivalioglu $M$, Esen $S$, Sunbul M, Leblebicioglu H. Detection of hepatitis B Virus in used razor blades by PCR. Hepat Mon. 2010;10(1):22-25.

32. Gil M. Riesgos psicosociales en el trabajo y la salud ocupacional. Rev Perú Med Exp Salud Pública. 2012;29(2):237-241.

33. Chile. Asociación Chilena de Seguridad (ACHS).Gerencia de prevención Prevención de riesgos en peluquerias [en línea]. Santiago: ACHS; 2009 [consultado feb2013]. p.1-8. Disponible en: http://www.achs.cl

34. Venezuela. Instituto Latinoamericano de Investigaciónes Sociales (Ildis). Informe social 10 [en línea]. Caracas: ILDIS; 2005 [consultado feb 2013]. Disponible en: http://libraryes.de/pdffiles/bueros/caracas/informe\%20social/ informesocial 10.pdf

35. Rosenstock I. Why People Use Health Services. New Jersey: John Wiley \& Sons; 2005. 